\title{
Study on Stability of Tall Buildings Under Earthquake
}

\author{
Zhang Xiang-Dong*, Fan Shi-Xing,Wang Pu and Guan Jian
}

Liaoning Technical University, College of Civil Eniineering and Transportation, Fuxin, Liaoning 123000, China

\begin{abstract}
Analysis of the structure characteristics of the high-rise building, through the instrument observation, obtains each observation point's total of subsidence and maximum subsidence, found no settlement of building site. Using the finite element software for structural modeling, modal analysis shows that the quality of structural system, the stiffness is more evenly distributed the structure of the torsional capacity to meet the requirements. The model input Tianjin wave, analyzes the dynamic characteristics of the model, the results showed that: structure below the middle and lower classes, with the building height decreases, the horizontal displacement of reducing the magnitude of the structure of the middle and upper classes, with the building height increases, the horizontal displacement increases, a lesser extent; frame - shear wall structure, shear walls there are substantial limitations in the bottom of the lateral displacement, compared with the upper structure of the lateral displacement limit capacity.
\end{abstract}

Keywords: Building settlement, Tianjin wave, Modal analysis.

\section{INTRODUCTION}

With the development of modern construction technique and materials science, modern building structure trended to longer and gentler. In order to design and monitor this kind of structure's vibration effectively and preventing the occurrence of disastrous consequences, it is often needed to analyzes and predict the structure's self-vibration characteristics and dynamic performance accurately and quickly in projects [1]. Engineering site is the carrier of seismic wave propagation, seismic wave propagation characteristics in different engineering site are difference [2]. Tall building structure in dynamic response will expose many problems, which are difficult to find by using static analysis methods. By means of dynamic analysis, the weakness of structure to be strengthened in advance can be discovered.

\section{PROJECT OVERVIEW AND ANALYSIS OF SUB- SIDENCE MONITORING}

\subsection{Project Overview}

The foundation of Fuxin Mining Group General Hospital Emergency Center for comprehensive building is frame structure, project has a total construction area of 28972.2 square meters, the building area of 1556.66square meters, the height of the building68.1m, a total of 17layer, 18layer of local, one layer upon layer height is $4.2 \mathrm{~m}$, two layers of high $3.6 \mathrm{~m}$, three $\sim$ five layer for $3.9 \mathrm{~m}$, six $\sim$ eighteen layer for $3.6 \mathrm{~m}$, the height difference of indoor and outdoor $0.9 \mathrm{~m}$.

*Address correspondence to this author at the Liaoning Technical University, College of Civil Eniineering and Transportation, Fuxin, Liaoning 123000, China; Tel: (86) 0418-3350627; 013841807278;

Fax: (86) 0418-3351902; E-mail: zhxd2008@yahoo.com.cn

\subsection{Observation Programs and the Implementation of Project}

\subsubsection{Datum Point Observation}

According to the technical design observation beginning after basis points buried a week later, 3 datum points constitute a close link. The first sensor observation has two roundtrip observations.

\subsubsection{Observation Point Observation}

(1) Observation route

Each will have 13 observation points, three known points together to form a circular observation line. Each measured by a standard of basis points, as much as possible in accordance with the original observation line observation, each observation is combined with the actual situation, and is completed in one day.

(2) Observing technical requirements and schedule

According to the technical requirements, the first observation after the laying of the vertical displacement of the observation point is completed in 24h. Observation cycle: start continuous observations 3 times, then every $3 d-7 d$ an observation, to meet the requirements of owners.

(3) The end time of vertical displacement observation

When the average speed of overall sinking of the observed is less than $0.01 \sim 0.04 \mathrm{~mm} / \mathrm{d}$, the sinking speed has entered a stable stage, meet the design requirements, and due to the restrictions of construction conditions, most points cannot be observed, thus the observation is completed. 


\subsection{Observation Point Layout and Task Completion}

\subsubsection{Datum Point}

In accordance with actual requirements, a total of laying and observed J1, J2, J3, J4, G1, G2, and G3, 6 six datum points. The former and the later periods used J1, J2, J3 three known points; the mid period used G1, G2, G3 three known points.

\subsubsection{Observation Point}

(1) A total of lying and the implementation of the observation point of observation: A1, A2, A3, A4, A5, A6, A7, A8, A9, A10, A11, A12, A13,

(2) Field observations collected 33 times of the settlement of original data;

(3) Total the maximum subsidence;

(4) The observation tolerance to meet the design requirements, the speed of last several observations calculated sinking about $0.02 \mathrm{~mm}$, in the range of $0.01 \sim 0.04 \mathrm{~mm}$, has entered a stable stage, and stop the observation;

(5) Obtained points sinking of the total statistics and the maximum subsidence after each observation.

\subsection{Analysis of Observations}

From Figs. $(\mathbf{1}, \mathbf{2})$ shows, in the whole period of observation, the largest total subsidence of observation is $4.64 \mathrm{~mm}$, the average of total subsidence of observation is $2.37 \mathrm{~mm}$, the largest maximum subsidence of observation is $6.54 \mathrm{~mm}$, the average of maximum subsidence of observation is $3.34 \mathrm{~mm}$;meet the stability requirements.

\section{THE DYNAMICS ANALYSIS OF HIGH-LEVEL STRUCTURE}

\subsection{The Analysis of Frame - Shear Wall Mixed Model}

The vibration characteristics of high-rise building are its inherent mechanical properties, it is a measure of the structural mass and stiffness to match the stiffness whether an important indicator, but also a necessary prerequisite for spectrum analysis and transient kinetic analysis. The analysis of structure model by the finite element software can get some useful data. Modal analysis is linear steady system vibration differential equations in physical coordinates will be transformed into modal coordinates, so that the decoupling of the equations become a set of independent equations described in the modal coordinates and modal parameters, in order to find the system modal parameters [3]. ANSYS software is large general-purpose finite element analysis software $[4,5]$, intuitive interface, has been widely used in structural mechanics, structural dynamics, heat transfer, fluid mechanics, and so on.

\subsection{Modal Analysis Method}

Multiple degrees of freedom undamped structural system, free vibration equation is as follows:

$$
[M]\{\ddot{u}\}+[K]\{u\}=\{0\}
$$

Where: $[\mathrm{M}]$ is the quality of the n-order matrix; $[\mathrm{K}]$ is the stiffness matrix of order $\mathrm{n} ;\{u\}$ is the acceleration vector; $\{u\}$ is the displacement vector.

Depending on the nature of the system of free vibration, structural vibration characteristics of the problem come down to in the Eigen value equation.

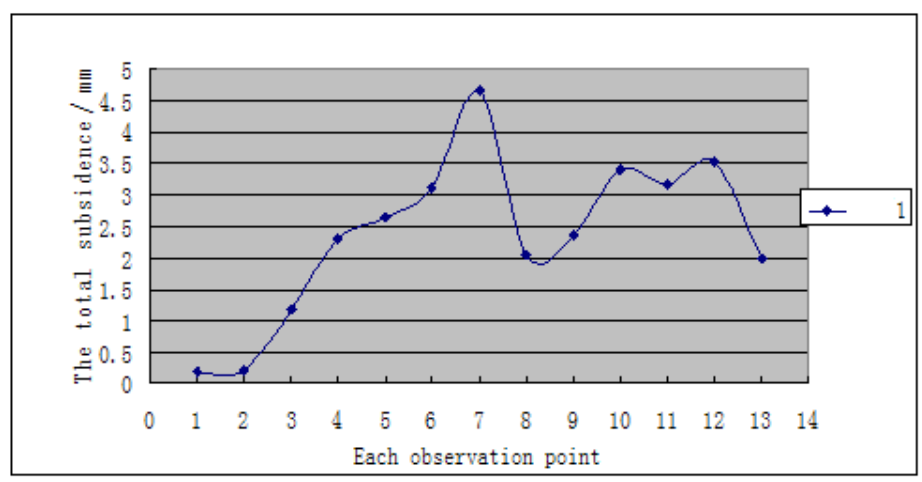

Fig. (1). The total subsidence of each observation point.

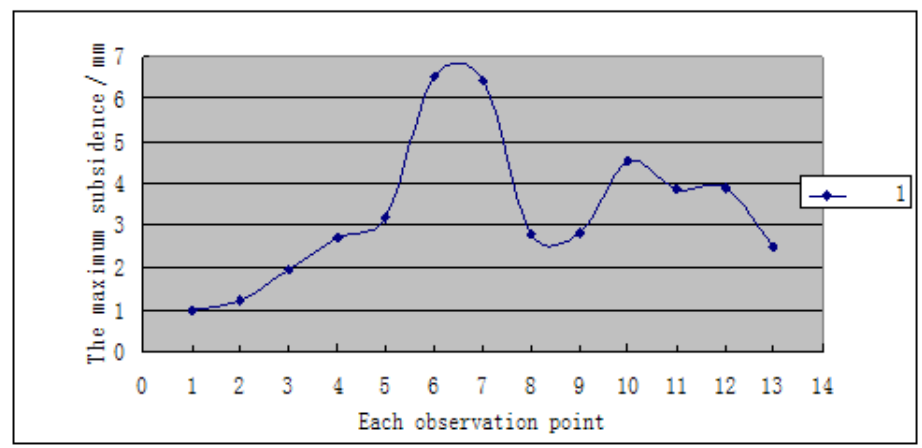

Fig. (2). The maximum subsidence of each observation point. 


$$
\left([\mathrm{K}]-\omega^{2}[\mathrm{M}]\right)\{\phi\}=\{0\}
$$

Modal analysis is solving the Eigen value equation of the Eigen value $\omega_{1}$ and its corresponding feature vector $\left\{\phi_{1}\right\}$. According to the Cramer rule we can see, the above equation if non-zero solution, only to meet:

$\left\{[\mathrm{K}]-\omega^{2}[\mathrm{M}]\right\}=0$

Equation for the characteristic equation of the system (or frequency equation), the natural frequency is the root of the characteristic equation system. For $\mathrm{N}$ natural frequency, the frequency is only relating to the system parameters. The Eigen value problem is equivalent to the demand equation (3) the root.

\subsection{Results of Modal Analysis}

Seismic analysis of high-rise buildings relies on calculation methods and mechanical model of support [6]. Using subspace method for the analysis of the model structure, Table 1 shows the ten order frequency in the high-level structure.

The first mode of the model for the $\mathrm{X}$ direction, the overall level move, the corresponding frequency is $1.465 \mathrm{~Hz}$, corresponding to the maximum displacement of $1.65 \mathrm{~mm}$; second mode for the Y direction as a whole translational, corresponding to the frequency $2.536 \mathrm{~Hz}$, corresponding to the maximum displacement of $1.16 \mathrm{~mm}$. The first and the second

Table 1. High-rise Structure before Ten Frequencies

\begin{tabular}{|c|c|c|c|}
\hline Order Number & Frequency & Order Number & Frequency \\
\hline \hline 1 & 1.465 & 6 & 5.985 \\
\hline 2 & 2.536 & 7 & 6.254 \\
\hline 3 & 3.157 & 8 & 6.435 \\
\hline 4 & 4.674 & 9 & 6.847 \\
\hline 5 & 5.257 & 10 & 7.135 \\
\hline
\end{tabular}

Table 2. Seismic Analysis of Horizontal Displacement of Structure

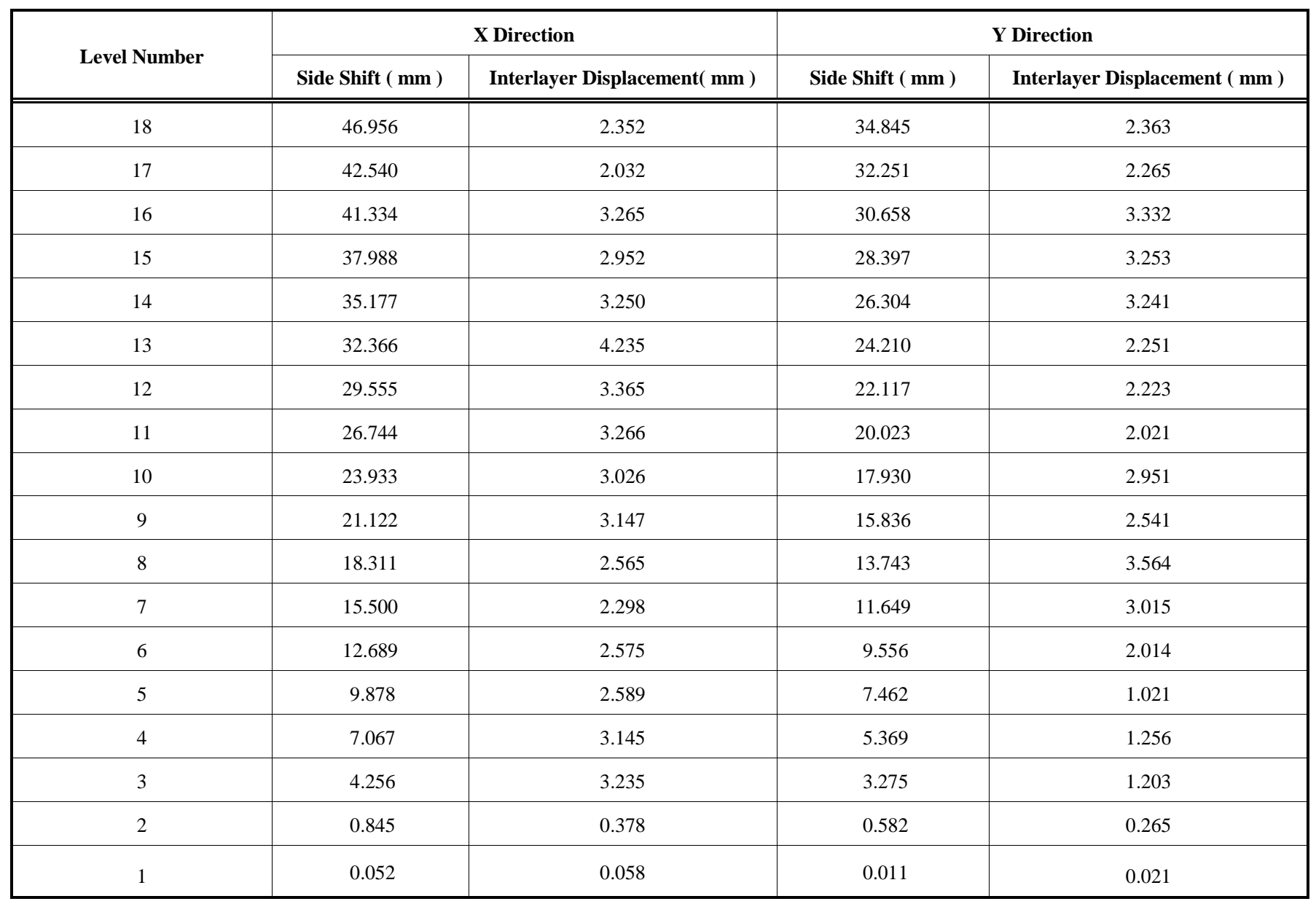


vibration modes along with the height were tested bending type displacement distribution that is the bottom of the deformation is small, while the upper part of a larger displacement and the first main mode $\mathrm{X}$-direction displacement is greater than the second vibration mode $\mathrm{Y}$ direction. The maximum displacement, which is due to the long axis of the structure of the $\mathrm{X}$ direction, the larger spacing of shear wall arrangement along with the $\mathrm{X}$ direction, $\mathrm{Y}$ direction for the short axis direction, and arranged along with the $\mathrm{Y}$ direction shear wall spacing is smaller, so that the $\mathrm{X}$-direction stiffness than the direction is smaller, so the structural vibration controls the direction of the $\mathrm{X}$ direction. Distribution of point of view from the torsional deformation, the overall coordination is strong; there is significant local displacement amplification, note the symmetry of the structural system layout, rules reasonable, the quality of the facade, the stiffness distribution is more homogeneous structure of torsional capacity to meet the requirements.

\section{THE TIME-HISTORY DYNAMIC ANALYSIS OF HIGH-RISE STRUCTURE UNDER SEISMIC LOAD}

Structures in earthquake damage effect depend on the dynamic characteristics of earthquake and dynamic characteristics of structure. Seismic dynamic characteristic can be determined by seismic amplitude of vibration, frequency and duration to describe; structural dynamic characteristics including natural period of vibration, vibration and damping [7]. China's seismic design [8] specification: Special irregular building, a building and the specific conditions of the high-rise buildings should adopt the time-history analysis method for calculating. Time history analysis method can be used to calculate the elastic structure, it can also be used to calculate the elastic-plastic structure, considering structural cracks or yield caused by structural changes in stiffness, and therefore can understand the part of structure where damage may appear [9]. Time history analysis method, the input seismic waves to determine the time history analysis results whether both reflect the structure may suffer earthquake, but also to meet the seismic design requirements for safety and function of the premise [10].

\subsection{Analysis Method}

Newmark method is adopted for numerical integration, iterative solution. The original record of the seismic wave time interval is $0.02 \mathrm{~s}$, take the step size is $0.0045 \mathrm{~s}$ to improve the accuracy of iteration, to ensure iterative convergence; in the loading process, step by step loading in the $\mathrm{X}$, $\mathrm{Y}$ directions separately applied to seismic excitation.

\subsection{Analysis of Seismic Response}

Structure's side shifts with the change of the floor under seismic wave more evenly. To the top of the structure under the Tianjin wave deformation is more obvious, especially in the structure of the upper floors, analytical structure of the drift angle, can be seen in the $\mathrm{X}$ direction near the 15-storey drift angle mutation and Tianjin wave is more obvious, and the displacement angle of the structure in the $\mathrm{Y}$ direction is relatively uniform.

It can be seen from Figs. (3 to 5) X-direction of top-level positive and negative displacement value the time interval are around 1.55, Y direction of the top level of the maximum positive and negative displacement value interval for the 1.155 or so, which can be seen that the maximum displacement value of seismic waves for the horizontal direction of the cycle are not affected.

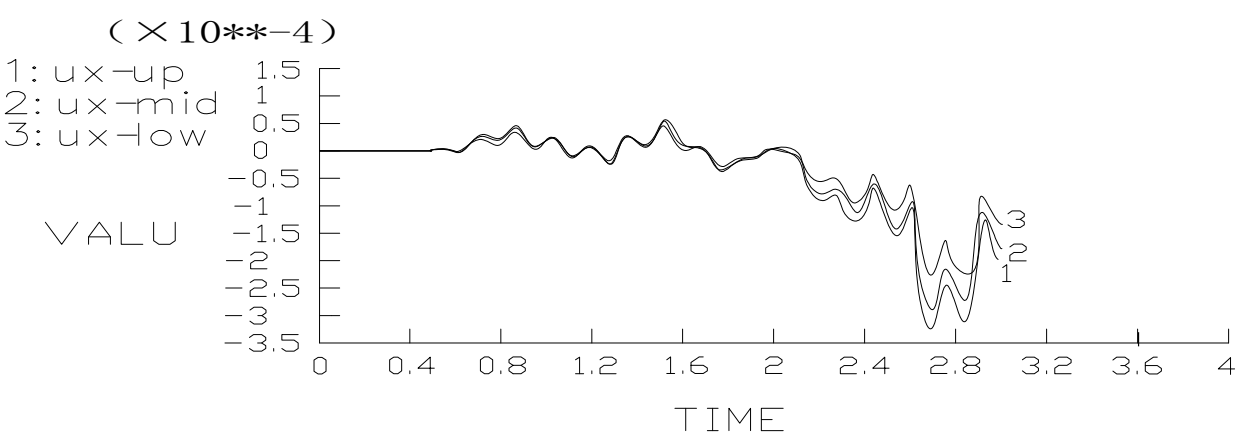

Fig. (3). Tianjin wave high-rise structure samples each point $\mathrm{X}$ direction displacement curve.

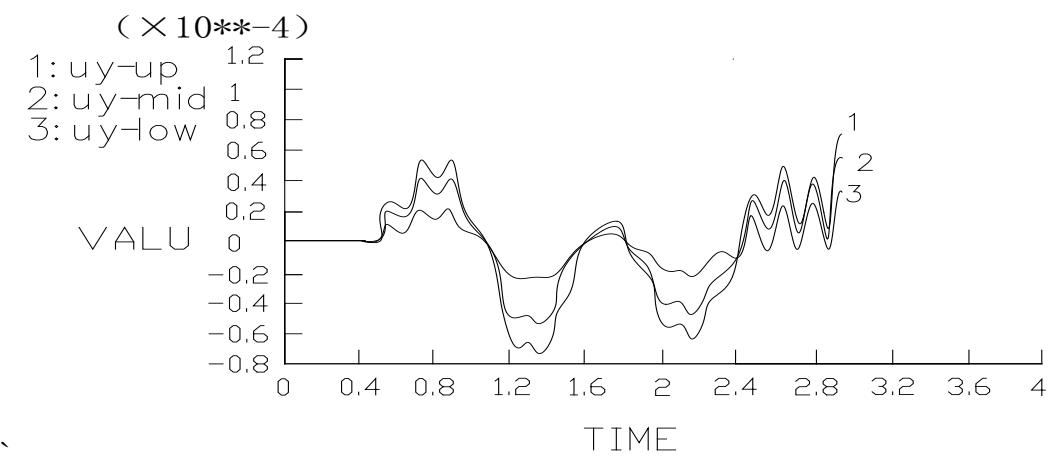

Fig. (4). Tianjin wave high-rise structure samples each point Y direction displacement curve. 


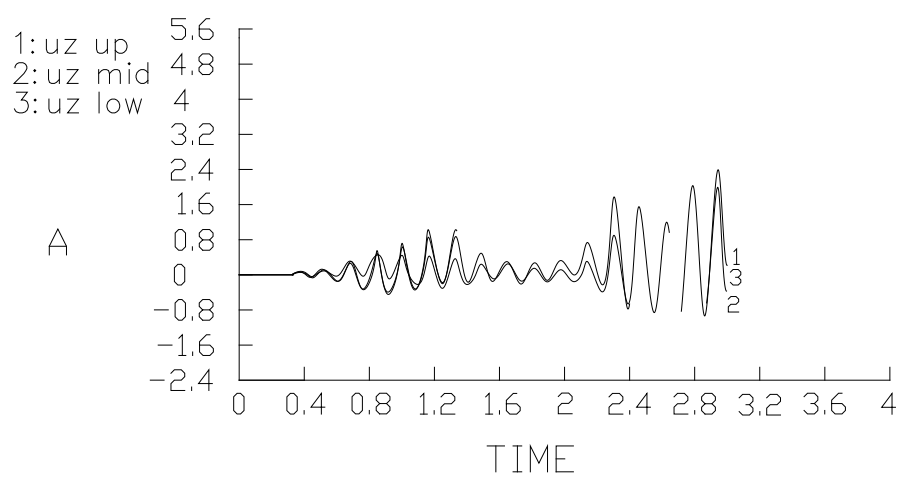

Fig. (5). Tianjin wave high-rise structure samples each point $\mathrm{Z}$ direction displacement curve.

\section{CONCLUSION}

In this paper, through large-scale finite element software ANSYS on Fuxin Mining Group General Hospital Comprehensive building frame structure numerical simulation analysis is carried out, including the structure of the modal analysis and dynamic analysis, concluded as follows:

(1) Monitoring results show that high-level structure of the settlement stabilized after construction is completed and no excessive settlement of parts of the settlement of high-level structure;

(2) The design of the frame - shear wall structure layout symmetry, reasonable rules, the quality of the facade, the stiffness distribution is more homogeneous structure of torsional capacity to meet the requirements, has a good overall performance, suitable for the calculation of;

(3) Structure below the middle and lower classes, with the building height decreases, the horizontal displacement of reducing the magnitude of the structure of the middle and upper classes, with the building height increases, the horizontal displacement increases, a lesser extent; frame - shear wall structure, shear walls there are substantial limitations in the bottom of the lateral displacement, compared with the upper structure of the lateral displacement limit capacity.

\section{REFERENCES}

[1] C-J. Fu and W. Zhang, "Finite element simulation of modal analysis in structural dynamics by parallel computing”, Mechanics and Practice, vol. 28, no.2, pp. 16-20, 2006.

[2] Y-Y. Li, Y. Xu and D-M. Li, "The analysis of different kinds of site seismic response”, Earthquake Research in Shanxi, vol. 26, no. 4, pp. 27-33, 2005.

[3] D-B. Wang and Z-Y. Chen, "Modal analysis of multi-layer framework based on ANSYS", Sci-Tech Information Development and Economic, vol. 21, no. 34, pp. 211-214, 2011.

[4] E. Madenic and I. Guven, "The finite element method and applications in engineering using ANSYS, Springer: NewYork, 2006.

[5] Y. Nakasone, S. Yoshimoto and T. A. Stolarki. Engineering Analysis with ANSYS software, Oxford; Boston, MA : ButterworthHeinemann, 2006.

[6] Y-S. Yu and W-X. Zhong, "Aseismic Analysis of the Whole Structure of Tall Building” The Building Structure, vol. 2, pp. 3-7, 1998.

[7] M.-S. Guan, Da-J. Han and H-B. Du, "A new seismic performance index for reinforced concrete frame structures”, Shen Zhen University Science and Engineering Ed, vol. 8, no. 3, pp. 200-205, 2011.

[8] GB50011-2001. "The Building Code for Seismic Desig”. Architecture and Building Press: Beijing, 2001.

[9] S-C. Zang and L. Kong, "Damping Analysis of the Mild Steel Damper to the Structures of Large Space at Bottom”, Special Structure, vol. 28, no. 5, pp. 77-81, 2011.

[10] Y-Y. Wang, "A review of seismic response spectra, time history analysis and energy method", Journal of Building Structures, vol. 21, no. l, pp. 21-28, 2000. 